\title{
Understanding the price drivers of successful apps in the mobile app market
}

\author{
Paolo Roma* \\ DICGIM - Management and Economics Research Group, \\ Università degli Studi di Palermo, \\ Viale delle Scienze, 90128, Palermo, Italy \\ Email: paolo.roma@unipa.it \\ *Corresponding author
}

\section{Gandolfo Dominici}

SEAS - Polytechnic School,

Università degli Studi di Palermo,

Viale delle Scienze, 90128, Palermo, Italy

Email: gandolfo.dominici@unipa.it

\begin{abstract}
In this paper, we take the perspective of app developers. Specifically, based on a sample of top paid apps from three major app stores, i.e., App Store, Google Play, and Blackberry World, we construct a hedonic price model to examine the role of relevant factors in price formation in the app market. Our results suggest a strong evidence of two-sided market effects. In fact, the lower price charged for apps operating as two-sided markets reflect the strategy of subsidising users, due to the positive cross-side externalities they exert on valuable third parties. Surprisingly, the effects of trialability, in-app purchase and mechanisms to build reputation are not significant in the context of successful apps. Finally, we find weak evidence that developers of top paid apps prefer price skimming to penetration price strategies.
\end{abstract}

Keywords: mobile app market; online distribution; pricing; two-sided market.

Reference to this paper should be made as follows: Roma, P. and Dominici, G. (2016) 'Understanding the price drivers of successful apps in the mobile app market', Int. J. Electronic Marketing and Retailing, Vol. 7, No. 2, pp.159-185.

Biographical notes: Paolo Roma is an Assistant Professor of Marketing at the University of Palermo, Italy. He received his $\mathrm{PhD}$ in Industrial Engineering and Management from the same university in 2009. He has been a Visiting Scholar at the University of California at Davis, University of Pittsburgh, and Toulouse School of Economics. His research focuses on topics at the interface between marketing and operations management, such as online distribution channel management, online pricing, mobile app market, and innovative business models on the internet. Outlets of his research include Operations Research, Production and Operations Management, International Journal of Production Economics among others.

Gandolfo Dominici is an Associate Professor of Marketing at the Department SEAS of the University of Palermo (Italy). He is the Scientific Director of the Business Systems Laboratory. He is a board member of the World Organisation 
of Systems and Cybernetics (WOSC), of the International Society for the Systems Sciences (ISSS) and of the Consorzio Universitario di Economia Industriale e Manageriale (CUEIM). He is the author of more than 65 published articles and books. He is the Editor-in-Chief of three and member of the editorial board of 13 international journals. His main research interests are: marketing, e-marketing, new product development, systems thinking and organisational cybernetics.

\section{Introduction}

Receiving breaking news, instant messaging with friends at every moment of the day, categorising portable songs, killing waiting time with tricky games are only some of the numerous routine activities many people perform using apps. Essentially, people download apps to increase the number of functionalities of their mobile device and, thus, carry a set of easy tools useful for the most disparate purposes, just like a sort of Swiss army knife available in their pockets. Indeed mobile apps have the potential to personalise the users' experience at any time and everywhere they like (Palumbo et al., 2014). The impressive impact of apps on people's everyday life can be quantified by exemplificative numbers. Recent industry statistics suggest, in fact, that the time per day spent by US consumers using apps increased by $35 \%$ in 2012, and was higher than the time spent on the web and quite close to that spent watching TV (Keynote Competitive Research, 2012; Khalaf, 2012; Nielsen, 2012). Also, numerous relevant industry studies report that the market is literally booming. Recent estimates provided by Gartner Inc. suggest that the revenue generated from customers buying and downloading apps for smartphones and tablets will step from \$26 billion in 2013 up to $\$ 77$ billion in 2017, whereas the number of downloads will increase from 102 billion to 268 billion (Gartner, 2013; Lunden, 2013).

However, apps for mobile devices have been around approximately since the late 1990s. Initially the market was dominated by mobile network operators (MNO), that constructed a highly centralised model with substantial, but yet not fully exploited, market potential (Kuo and Yu, 2006; Ghezzi et al., 2010). This context was revolutionised in 2008 by Apple that, launching the App Store, introduced the application store distribution paradigm in Mobile Commerce. The strategies of leveraging on strong assets such as brand reputation and the iPhone innovation, of linking the App Store to other businesses, i.e., iTunes, and of incentivising third party independence and revenue sharing allowed Apple to change the rules of the game, relegating MNOs to a marginal role and opening the gates to new players (Ghezzi et al., 2010). In fact, in response to the great success obtained by Apple, since 2008, several big mobile device manufacturers, such as RIM Blackberry, Samsung and Nokia, have launched their own app stores. This rapid proliferation of app stores has also involved Google, that launched the Android mobile operating systems (OS) and made the Google Play (initially Android Market) available to users in 2008, Microsoft, that launched Windows Marketplace for Mobile (later, Windows Phone Store) and, more recently, Amazon, that introduced the Amazon Appstore. Currently, App Store and Google Play are by far the most popular stores ${ }^{1}$. Microsoft and RIM Blackberry platforms precede other players. However, while App 
Store generates the highest total revenue, numerous sources indicate Blackberry World as the most profitable store to developers (Rocha, 2012; VisionMobile, 2012).

An application store is an online distribution platform from which a user can download apps developed by third parties for mobile devices supported by the platform. However, it does not resemble a traditional online retail model (e.g., Chen et al., 2014), where the reseller charge a price based on wholesale price set by product providers. Rather, the price is set by developers who, according to a pre-determined sharing rule set by the app store owner, appropriate most of the revenue for each transaction $(70 \%$, in all the major stores), whereas the store owners retain the remaining. In fact, an app store can be categorised as a two-sided market, i.e., an economic platform attracting two distinct groups of users, developers and consumers in this case, who provide each other with intra- and/or inter-network benefits (Rochet and Tirole, 2003). By means of an app store, a multitude of developers can reach a vast scale of consumers worldwide, that they might not be able to reach on their own. On the other hand, consumers download apps to satisfy a number of needs and, thus, increase the utility associated with the usage of their mobile device. Finally, the distribution platform can derive a direct benefit appropriating a portion of revenue for each transaction in the store, and a much higher indirect benefit from the increased value of their correlated businesses, e.g., mobile devices. The presence of these interactions among all the involved actors is a unique feature, which distinguishes the mobile app market from traditional two-sided markets.

The rapid growth of the app market offers numerous business opportunities to a multitude of developers, which, however, imply facing several important decisions (Palumbo and Dominici, 2015). To cite a few of them, developers have to choose what and how many apps to market, which app store to target, which business model to adopt for their apps, and how to price them. However, while tons of articles have been available online from numerous media since its birth, the mobile app market has started attracting researchers only very recently. The delay may be explained by the fact that, due to its recent constitution, no databases organising relevant information have been available in the market, which poses a serious obstacle to the above scientific purposes. The main sources of data remain app stores themselves, with the exception of a few research firms specialised on the market. This causes non-trivial problems of data collection as well as lack of some important data. The consequence is that there are only few relevant works focusing on this intriguing market to investigate issues related to demand estimation (Carare, 2012; Garg and Telang, 2013; Ghose and Han, 2014).

In this paper, we also take the perspective of developers. However, we construct a hedonic price model and test a number of hypotheses to examine the role of relevant factors in price formation in the app market. Specifically, with the support of a rich dataset built ad hoc, we investigate price formation for top paid apps, i.e., the most popular paid apps. As our focus is on price rather than sales estimation, our work complements the above studies shedding light on this important, yet understudied, market with regard to price decisions of successful apps. We also significantly contribute to the relevant literature on hedonic price of software products (Gandal, 1994; Brynjolfsson and Kemerer, 1996; Gallaugher and Wang, 2002) providing novel evidence from a new market having some distinctive features. In fact, differently from most of software markets studied in this literature, the app market is characterised by a unique distribution model, which, with negligible entry barriers and the implementation of various mechanisms [software developer kit (SDK), feedback systems, etc...], facilitates access to a multitude of developers and consumers. As a result, a multitude of products 
satisfying the most disparate needs are offered in the same competitive arena. Also, a further peculiar feature of this market is that the type of consumers having access to a given store strictly depends on the characteristics of consumers purchasing the mobile devices supported by that store. Finally, apps are, in general, characterised by frequent usage, marked easiness to use, limited prices, and might operate themselves as two-sided markets. By performing a cross-store analysis using data from the most relevant app stores, namely App Store, Google Play and Blackberry World, our paper advances understanding of some existing theories by testing the role of known price determinants in a new market. Specifically, we study whether software developer practices, such as the adoption of a two-sided market business model, the introduction of free trial versions, the adoption of a version-to-upgrade model (commonly referred to as in-app purchase in the app market), are relevant to price decisions in the context of successful apps. Also, we investigate the role of the introductory pricing policy chosen by developers. Unravelling the effect of these factors may support developers' future price decisions. Finally, we also examine the role of online mechanisms to build reputation (e.g., ratings), which, although extensively studied in the literature on online commerce, are absent in previous studies of hedonic price of software products. In this case, we explore whether there exists a strong rationale behind the use of such mechanisms.

By way of anticipation, our results demonstrate a strong impact a strong two-sided market effect. Specifically, in accordance with economic theory, the lower price charged for apps operating as two-sided markets reflect the strategy of subsidising the mass of end users, due to the positive cross-side externalities they exert on valuable third parties, e.g., advertisers. Surprisingly, the effects of free trialability, upgrading via in-app purchase, and mechanisms to build reputation are not significant. For these results we provide tentative explanations, which relate to the characteristics of successful paid apps. Finally, we find weak evidence that developers of top paid apps utilise a price skimming strategy, as apps first released are associated with higher prices. This result suggests that the benefits derived taking advantage from customer heterogeneity might prevail over those obtainable setting low introductory prices and exploiting network externalities among users. Overall, we believe that our results serve to compose a first useful picture of price drivers in the app market, showing how different from other software markets the app market could be with regard to the effect of certain factors on price.

The paper is organised as follows. We first discuss the theoretical background and introduce the hypotheses. Then, the econometric analysis is presented. In turn, we describe the dataset, the explanatory variables and the regression model, discuss empirical findings and relative implications, and provide several extensions of our model. Finally, we conclude.

\section{Theory and hypotheses}

\subsection{The hedonic price model}

Our paper builds upon the well-known theoretical model of hedonic price (Rosen, 1974). Hedonic price models are utilised to estimate how different features of a differentiated product contribute to the utility customers derive from the product, and, thus, their willingness to pay. Under this model, the price is the resulting function of product 
attributes' implicit prices. The implicit price of a given product attribute corresponds to the consumers' willingness-to-pay for a unit increment of the level of that attribute.

The hedonic regression model is fully consolidated in empirical literature and has been used for price estimation of a wide variety of products and services. A historical summary of this literature can be found in Berndt (1991). There have been a considerable number of applications to information technology products. Hardware products have been considered first (Chow, 1967; Berndt, 1991). More recently, attention has been shifted to include also software products in hedonic analyses (Gandal, 1994, 1995; Brynjolfsson and Kemerer, 1996; Gallaugher and Wang, 2002). These studies mainly demonstrate the existence of network externalities in software markets and the relative beneficial impact on price formation. Our paper share similarities with these studies as we construct a hedonic model to investigate the effect of relevant price determinants in the software market. However, we are interested in exploring price formation of a particular software product category, i.e., mobile apps, due to the specificities of this market as well as the popularity gained in the very last few years. We study of the role of factors, such as trialability, to point out notable differences from former works on hedonic price of software products. In addition, some determinants, such as the online mechanisms to build reputation or the opportunity to upgrade to more complete versions, while common in other streams of literature, have not been incorporated in the above studies on hedonic price estimation of software products. Finally, compared to Gallaugher and Wang (2002) who also analyse the effect of two-sided market externalities, we take a different perspective. In fact, they explore whether firms with a greater installed market base on one side of the network (web browser market) will enjoy a higher price on other side (web server market) than rivals with smaller market-base. We study how the price charged to end users will be modified as a consequence of the existence of cross-side externalities when apps operate as a two-sided market. Our model is enriched including several control variables, which help provide more accurate estimates. Next, we present and discuss hypotheses in detail.

\subsection{Two-sided market effect}

Many real markets with network externalities exhibit the characteristics of a two-sided market. Some examples of two-sided platforms include e-marketplaces (where suppliers and buyers are the two sides of the market), social networks (users and advertisers), game consoles (gamers and game developers), TV and other media (viewers/readers and advertisers) (Rochet and Tirole, 2003; Parker and van Alstyne, 2005). For surveys of the theoretical literature on two-sided markets readers can refer to Rochet and Tirole (2006). A two-sided market is characterised by the existence of cross-side externalities. That is, the demand from one side strongly depends on the demand from the other side, and vice versa. Also, in many cases, users on one side will be attracted to the platform only if a critical mass of users on the other side is reached. The existence of cross-side externalities and the relative magnitude drastically impact on pricing strategy. As a matter of fact, when setting a price for each side, platform owners should factor in the impact of each side on the other side's growth and willingness to pay. Otherwise they might end up suffering substantial revenue losses. Broadly speaking, in a two-sided network we can identify a 'subsidy side' and a 'money side' (Eisenmann et al., 2006). The first group, when consisting of a high number of users, is highly valuable to the second group. A profitable pricing structure would therefore imply to target aggressively, 
i.e., subsidise, the side of users who are able exert a larger positive externality on the other side, and monetise from the latter abundantly (Rochet and Tirole, 2003; Parker and van Alstyne, 2005; Armstrong, 2006; Rysman, 2009) ${ }^{2}$. Very few studies provide empirical evidence of how the presence of two-sided network externalities influences the pricing structure (Evans, 2003; Kaiser and Wright, 2006). For instance, in full accordance to the theoretical predictions, German magazines seem to subsidise readers and make profit from advertisers as the latter group, instead of the former, value the opposite side more (Kaiser and Wright, 2006). Evidence of cross-side externalities can be found also in Gallaugher and Wang (2002), although they focus on whether firms with a greater installed market base on one side (web browser market) will enjoy higher price on the other side (web server market) than rivals with smaller market-base.

Depending on the specific business model adopted by the developer, apps might operate as a two-sided market attracting app users on one side and interested third parties on the other side. Interested third parties could be advertisers or info seekers, i.e., firms seeking information about consumers for specific business purposes. In fact, a considerable number of paid apps, such as games among the others, contain third parties' advertisements. Furthermore, developers of certain apps, such as social networking applications, centre their revenue model on building a large user-base to attract info seekers and, thus, earning from non-personally identifiable information selling (Williams, 2009). Therefore, according to the theory, if there exist strong cross-side network externalities between app users and potentially interested third parties, and specifically app users exert an irresistible appeal to such actors, we should observe that apps operating as a two-sided market, e.g., ad-supported apps or apps collecting and selling data, have lower prices than those that do not exhibit such characteristics. As a result, we can formulate the following hypothesis:

- Hypothesis 1 (H1): prices of apps operating as two-sided markets are lower than those of apps that are not two-sided platforms.

\subsection{Trialability effect}

Many information goods, such as software, fall into the category of experience goods. That is, consumers can evaluate some of their features accurately only upon consumption. Exacerbated consumers' uncertainty about product value might be quite detrimental to sellers with a negative impact on price premiums (Dimoka et al., 2012). To cope with such an uncertainty, software developers often provide free trial versions of their products so that users can download to test them before purchasing. This is facilitated by the fact that, unlike physical goods, information goods entail negligible marginal costs for both production and online distribution. Free trial products are largely observable in the software market in two general forms: free fully functional versions with limited trial time, i.e., time-locked versions, and free 'demo' versions with notably limited functionalities, i.e., limited versions (Cheng and Liu, 2012). In general, trialability measures the extent to which potential adopters perceive that they have an opportunity to experiment with an innovation prior to committing to its usage (Rogers, 1983; Moore and Benbasat, 1991; Agarwal and Prasad, 1997). For instance, trialability has been shown to be crucial in the adoption of information technologies (Agarwal and Prasad, 1997). Both 
theoretical and empirical studies have examined the effects of using free trials or samples on variables, such as probability of purchase, price and profit, in case of physical goods (Scott and Yalch, 1980; Goering, 1985; Bawa and Shoemaker, 2004). More recently, some authors have investigated the effects of trialability in case of information goods (Gallaugher and Wang, 2002; Cheng and Tang, 2010; Cheng and Liu, 2012). Through a trial version users can test the product and resolve the uncertainty about its real value to them. Also, trialability can serve to signal product quality as the knowledge that a product is available in a free trial version is some sort of guarantee to customers (Gallaugher and Wang, 2002). For these reasons, it is expected that consumers will pay a higher price given the opportunity to test a product before buying. As a matter of fact, in the web server market, Gallaugher and Wang (2002) empirically find that products for which free trial versions are available are associated with price premiums. In fact, ceteris paribus, they show that firms offering a trial version enjoyed a price premium of roughly 110 to 120 percent. In addition to resolving consumers' uncertainty, the introduction of a free trial version helps exploit the network effects, which often characterise information goods. In presence of network externalities among users, releasing a free trial version supports a more effective diffusion of firms' new products (Cheng and Liu, 2012). In this case, consumers assign a higher value to the product due to the higher installed base. As a result, a positive effect of free trialability on price of the commercial product is expected. Results in Cheng and Liu (2012) are, in fact, consistent with this assertion.

Developers often release a free version associated with the paid version of their apps. Therefore, the app market is suitable to test for the existence of a positive effect of trialability. However, not all free app versions associated with paid app versions can be considered as proper free trial app versions. Based on our earlier discussion, only free versions offering very limited features or being time-locked are proper free trial versions. However, often a free app version differs from the corresponding paid version essentially because of (more intense) presence of ads. In these cases, the risk of demand cannibalisation for their paid products as a consequence of the introduction of a free version might be high, resulting in a significant price reduction for the paid product. More in general, some recent studies point out possible negative effects of free trial versions on the commercial product in presence of low product differentiation between them, e.g., when there are a few differences in terms of functionalities or the trial period is not sufficiently short (Bawa and Shoemaker, 2004; Smith and Telang, 2009; Cheng and Tang, 2010; Cheng and Liu, 2012). Therefore, it is important for developers to accurately design their free trial versions, reducing the degree of substitutability to a minimum. Otherwise, the free trial version would no longer serve as an opportunity to let consumer experiment with the product prior to committing to its usage. Rather, it would have the role of a possibly more appealing substitute. Due to our primary interest in the effect of trialability, in this paper, we distinguish between free trial version and free version, considering as free trial versions only those versions, which present very limited functionalities and/or a reasonably short trial period. With this distinction, we can follow Gallaugher and Wang (2002) and, thus, support the positive effects of the free trial version on app prices in the following hypothesis:

- Hypothesis 2 (H2): apps offering free trial versions to users have higher prices. 


\subsection{In-app purchase effect}

For numerous information goods consumers are often allowed to purchase additional features to the product version they have previously bought. This practice is commonly utilised also in case of apps, referred to as in-app purchase. Specifically, a user who has downloaded an app, e.g., a game, at a given price (or free) is given the opportunity to purchase additional features, e.g., additional game levels or credits, or upgrade to more complete product versions directly inside the app. In this way, in-app purchase allows developers to price discriminate highly valuable consumers who will upgrade to more complete product versions from less valuable consumers who will be content with the base version. In its essence, in-app purchase combines versioning and upgrading practices. There is a considerable amount of theoretical studies on versioning of information goods (Bhargava and Choudary, 2001, 2008; Wei and Nault, 2013). These works suggest that versioning is optimal only under certain conditions. For instance, nonlinear consumer utility function is necessary for versioning to be optimal (Bhargava and Choudary, 2008). Recently, Wei and Nault (2013) introduce, in a two-version setting, the possibility that consumers who bought the low quality version upgrade to the high quality version at a certain price. They show that, under the version-to-upgrade setting, versioning is optimal and there might be consumers who will upgrade to the high quality version after purchasing the low quality version. It is quite straightforward that the presence of two versions and the opportunity to upgrade help segment the market profitably so that the price of the version with basic functionalities is lower than the price the provider would charge if only one version was released. In line with this argument, we expect that developers giving the opportunity to in-app purchase will naturally sell the base version at a lower price, as opposed to developers who do not utilise such practice.

- Hypothesis 3 (H3): apps allowing in-app purchase of additional features have lower prices.

\subsection{Introductory pricing policy effect}

How firms should vary price over the product life cycle has been extensively studied in marketing literature. For surveys of this literature, readers can refer to Tellis (1986), Mahajan et al. (1990), Noble and Gruca (1999), and more recently Chatterjee (2009). Specifically, when introducing a new product, firms can balance between two extreme pricing strategies, namely market skimming or market penetration (Dean, 1950; Mahajan et al., 1990). Under a skimming strategy, firms initially set a high price targeting high valuable customers. Then, the price is gradually decreased attracting less valuable segments. Essentially, a skimming strategy allows, for new products, the implementation of inter-temporal price discrimination in presence of multiple segments that differ in value. On the other hand, a penetration strategy implies the use of a low price at first to capture a large market-base. Then, once the product is established in the market, the price can be raised. Normative results provided by the literature are somehow contrasting. Some studies support the former pricing strategy in presence of price impact on market potential, learning curve effect or the possibility that the product can be copied (Kalish, 1983; Nascimento and Vanhonacker, 1988). Furthermore, price skimming is preferable in presence of high customer heterogeneity and product differentiation (Dean, 1969; Tellis, 1986; Noble and Gruca, 1999). The latter pricing policy is predicted in presence of a 
strong 'word-of-mouth' effect of early adopters on late adopters and, more in general, in presence of network externalities. In this case firms might find optimal to subsidise early adopters with a low introductory price to stimulate their purchases and exploit network effects, and then increase the price when a large market-base has been created (Robinson and Lakhani, 1975; Dolan and Jeuland, 1981; Thompson and Teng, 1984). Empirical analyses of new product pricing practices in the most disparate industries tend to be in line with the normative results (Noble and Gruca, 1999). In fact, some empirical studies indicate that price skimming has a positive impact for high-tech products having innovative features (Yoon and Lilien, 1985; Beard and Easingwood, 1996). Other studies highlight that in presence of significant network effects, e.g., in case of information goods, firms often use a low introductory price to reach a large market-base quickly (Shapiro and Varian, 1999; Lee and Colarelli O’Connor, 2003; Dubé et al., 2010; Liu, 2010).

Apps reasonably belong to a product category subject to network externalities. Therefore, the existence of considerable word-of-mouth and other network effects among users should induce developers to utilise a penetration policy to exploit the advantage of a large installed market-base. In this case, ceteris paribus, apps first released should have a lower price than apps available in subsequent versions. However, numerous successful apps have unique features or might not be easily imitable or substitutable. Furthermore, for many apps there might exist users who are highly valuable. For instance, very passionate gamers can certainly afford to purchase their preferred app right after the release at any price. Developers might find optimal to skim this segment and later decrease the price to target less addicted users. In this case, ceteris paribus, apps first released should have a higher price than apps available in subsequent versions. Therefore, we can formulate two opposite hypotheses, each holding if a price skimming or a penetration price strategy is used, respectively:

- Hypothesis 4a (H4a): apps released in the initial version have a higher price than apps available in subsequent versions.

- Hypothesis $4 \mathrm{~b}(\mathrm{H} 4 \mathrm{~b})$ : apps released in the initial version have a lower price than apps available in subsequent versions.

\subsection{Reputation mechanism effect}

The effect of seller reputation on pricing decisions has been widely investigated in the literature. Economic theory typically suggests the existence of a positive relationship between seller reputation and price (Klein and Leffler, 1981; Shapiro, 1983). This is mainly because the seller reputation can be viewed in the long run as a proxy for quality characteristics that are unobservable to consumers before the transaction takes place. Some empirical studies conducted in the software industry have tended to support the theoretical results (Banerjee and Duflo, 2000). However, a significant number of empirical researches on this issue have flourished only after the introduction and growth of e-commerce. Different from offline markets, internet allows an easy implementation of mechanisms to build reputation, e.g., ratings, comments and reviews provided by buyers, which are commonly referred to as feedback systems (Bolton et al., 2004). Also, in the e-commerce environment, the importance of reputation increases as payment and delivery rarely occur simultaneously (Standifird, 2001). In fact, several recent studies empirically demonstrate that mechanisms to build reputation have positive effects on 
price as they are a vehicle to signal quality and increase customer trust in presence of uncertainty about product quality and/or seller reliability (Standifird, 2001; Ba and Pavlou, 2002; Bajari and Hortacsu, 2003; Livingston, 2005; Houser and Wooders, 2006; Pavlou and Dimoka, 2006; Resnick et al., 2006; Lucking-Reiley et al., 2007). However, it is noteworthy that there are a few studies in this strand of literature that point out that no reputational benefits, at least in terms of price premiums, are observed (Resnick and Zeckhauser, 2002; Kauffman and Woods, 2006). Also, whether reputation mechanisms allow firms to enjoy price premiums might depend on the type of metric used to measure such effect. For instance, in their study on price determinants in eBay, Lucking-Reiley et al. (2007) find that the summary measure (which takes into account both positive and negative feedbacks) has no influence on price, whereas negative feedbacks significantly impact on price. In a similar vein, negative feedbacks might be influential, whereas positive feedbacks might not (Lucking-Reiley et al., 2007), or vice versa (Ba and Pavlou, 2002; Bajari and Hortacsu, 2003). Also, in case of positive and statistically significant effect, the economic impact of reputation might not be relevant (Melnik and Alm, 2002). Dellarocas (2003) provides a comprehensive review of the whole stream of literature.

In spite of the reputation of app store owners such as Apple, Google and Blackberry and the adoption of more or less strict criteria through the release of SDKs that developers have to meet in order to market their apps on such platforms, users might still be uncertain about the real value an app can generate to them before they use it. For this reason, most of the app store owners offer to users the opportunity to rate the apps they download, and, as a result, provide a feedback about the quality level delivered by developers. In line with most of previous works, we hypothesise a positive influence of such reputation mechanisms on price. In addition to the effect of online rating mechanisms, there might be additional price premiums that are exclusive to those giant developers who have a fully established reputation worldwide. For instance, some app developers are giant companies or represent famous brands in the entertainment industry such as Electronic Arts, Activision Blizzard and Disney interactive ${ }^{3}$. According to the economic theory of reputation, the worldwide recognition reserved to such companies or brands should guarantee higher price premium returns, ceteris paribus. Combining the effects of the feedback systems and established worldwide reputation, we formulate:

- Hypothesis 5 (H5): developers of apps with higher ratings on average enjoy higher prices for their apps. In addition, apps of developers with fully established reputation worldwide have a higher price.

\section{The econometric model}

To test the formulated hypotheses, the following general hedonic price model is introduced:

$$
P_{i t}=f\left(T S_{i t}, T S_{i t}, I A_{i t}, I P_{i t}, R_{i t}, C_{i t}\right),
$$

where, for every observation unit $i$ and period $t, P_{i t}$ is the price, $T S_{i t}$ is the two-sided market attribute, $T_{i t}$ is the trialability attribute, $I A_{i t}$ is the in-app purchase attribute, $I P_{i t}$ is the introductory pricing policy attribute, $R_{i t}$ is the set of reputation attributes, and $C_{i t}$ is a set of control attributes. 


\subsection{Data}

To obtain all the relevant information required in (1), we built a dataset ad hoc collecting data of top (i.e., most downloaded) paid apps for smartphones by weekly exploring the Italian version of the major app stores, namely App Store, Google Play and Blackberry World. Specifically, we recorded data from the top paid app ranking publicly available in each of these platforms every Friday in the period going from 6 May to 23 December 2011 (34 observation periods in total). Data collection from top paid app rankings is in line with our objective of estimating the hedonic price function for successful apps. In addition, top paid app rankings are also utilised by Carare (2012) and Garg and Telang (2013) for their studies on the relationship between ranks and sales. It is noteworthy that app stores do not release detailed information about the criteria to compute top app rankings. However, several sources agree that app stores usually compile top app rankings based on sales within a 24 hours window (Carare, 2012). After a preliminary analysis with a larger rank range, we restricted to the top ten paid apps. In this aspect we differ from Carare (2012) and Garg and Telang (2013), who, instead, collect data mostly from top 100 and top 200 paid app rankings of the App Store, respectively. Our choice is due to the less automatable data collection effort in our case. In fact, while the data utilised by Carare (2012) and Garg and Telang (2013) are retrievable upfront from the app store, numerous data crucial to perform our analysis, such as whether the given app has ads in it or not, ratings of all the apps marketed by the given developer, number of apps marketed by the given developer, the presence of a free trial or free version, were not immediately retrievable and required subsequent accurate app analyses as well as extensive checks in the app stores and developers' websites. Furthermore, restricting to top ten rankings is perfectly in line with our objective of exploring price drivers of successful apps. It is in fact demonstrated that the relationship between rank and actual sales is very steep so the very first ranked apps account for most of the revenues in a store (Canalys, 2012; Farago, 2012). We also decided to access the rankings one day a week instead of doing it everyday because we noted that the composition of top ten rankings did not change significantly within a week, although top ten paid apps switched their ranks sometimes. Most importantly, our dependent variable, i.e., the price, (and, also time-variant explanatory variables) very rarely changed within a week. Therefore, extending our data collection to more than one day a week would have naturally yielded more observations, which, however, would have just been duplications of already available information in most of the cases. Our data collection frequency differs from that of Carare (2012) and Garg and Telang (2013) due to the different purposes. They collect daily data from larger rank ranges, but their observation period is shorter compared to our time span. The reason is because they study the relationship between ranks and sales. Thus, they need to collect samples involving large rank ranges, e.g., 1-200, and higher rank variability for each app, which can be obtained even with fairly short observation period, e.g., two months. On the other hand, we conduct a hedonic price estimation analysis. As a very low number of price variations can be encountered from a day to the subsequent, a longer time span and weekly data collection seem to be more appropriate in our study to increase the price variability for each app. 
It is noteworthy that all the distribution platforms also provide the top free app (i.e., the most downloaded free apps) ranking in addition to the top paid app ranking. However, we do not consider this ranking, as our intent is to provide a hedonic price analysis, which usually is conducted with non-zero prices. Also, paid apps still account for the highest percentage of the revenues generated in app markets (Serricchio, 2013; Lunden, 2013). Interestingly, App Store and Google Play also provide a top grossing app ranking (i.e., apps generating the highest revenue combining purchase price, advertising, in-app purchase and other revenue streams). Collecting data from such rankings would have also been appealing. There are two obstacles that induced us to consider only paid apps. First, Blackberry World and other stores do not provide this ranking, which would make the comparison impossible. Second, in both App Store and Google Play top ten grossing rankings, numerous apps are free.

After recording the top ten paid apps from the three stores for all the 34 weeks we obtained a rich dataset containing 1,020 observations. Due to our data collection procedure we did not know a priori how many apps would have been included in our sample. However, a significant number of apps were expected to rank in the top ten rankings for more than one week, which helps consider the temporal variability of price. As a matter of fact, the total number of observations, i.e., 1,020, is related to $299 \mathrm{apps}^{4}$, that have been at least once in at least one of the three rankings during the specified period. Thus, our sample is an unbalanced panel dataset where more successful apps carry higher weight in the analysis due to the higher number of times they appear in a ranking.

\subsection{Variables}

We define a set of variables to test our hypotheses. Table 1 summarises the description and the modalities of all the variables, whereas Table 2 shows the relative descriptive statistics.

Table 1 Variables description

\begin{tabular}{|c|c|}
\hline Variables & Description \\
\hline $\begin{array}{l}\text { App category (education; fun and } \\
\text { entertainment; games; healthcare and } \\
\text { fitness; money and finance; music; news } \\
\text { and info; photo and video; social network; } \\
\text { themes and customisation; transportation; } \\
\text { utility) }\end{array}$ & $\begin{array}{l}12 \text { binary variables, each equal to } 1 \text { if the app } \\
\text { belongs to the respective category; } 0 \text { otherwise. }\end{array}$ \\
\hline App size & $\begin{array}{l}\text { Continuous variable measuring the size (in Mbytes) } \\
\text { of the app in the given week. }\end{array}$ \\
\hline Developer fame & $\begin{array}{l}\text { Binary variable equal to } 1 \text { if the app developer is a } \\
\text { giant developer with established reputation } \\
\text { worldwide; } 0 \text { otherwise. Based on revenue } \\
\text { information and worldwide recognition we identify } \\
\text { ten top developers in our sample, i.e., Activision } \\
\text { Blizzard, Apple, Capcom, Disney Interactive, } \\
\text { Electronic Arts, Gameloft, Konami, Namco Bandai, } \\
\text { Sega Sammy, Take-Two Interactive. We also } \\
\text { include Marvel Entertainment and DC Comics due } \\
\text { to their huge popularity. }\end{array}$ \\
\hline
\end{tabular}


Table 1 Variables description (continued)

\begin{tabular}{|c|c|c|c|}
\hline \multirow{2}{*}{\multicolumn{2}{|c|}{$\begin{array}{l}\text { Variables } \\
\text { Developer rating (no developer rating; low } \\
\text { developer rating; medium developer } \\
\text { rating; high developer rating) }\end{array}$}} & \multicolumn{2}{|c|}{ Description } \\
\hline & & \multicolumn{2}{|c|}{$\begin{array}{l}\text { Four binary variables, each equal to } 1 \text { if, in the given } \\
\text { week and store, the app developer rating belongs to } \\
\text { the respective category; } 0 \text { otherwise. }\end{array}$} \\
\hline \multicolumn{2}{|c|}{ Developer type } & \multicolumn{2}{|c|}{$\begin{array}{l}\text { Binary variable equal to } 1 \text { if the app is developed by } \\
\text { a firm; } 0 \text { if developed by individual(s). }\end{array}$} \\
\hline \multicolumn{2}{|l|}{ In-app purchase } & \multicolumn{2}{|c|}{$\begin{array}{l}\text { Binary variable equal to } 1 \text { if the app allows in-app } \\
\text { purchase; } 0 \text { otherwise. }\end{array}$} \\
\hline \multicolumn{2}{|l|}{ Number developer apps } & \multicolumn{2}{|c|}{$\begin{array}{l}\text { Positive integer variable indicating the number of } \\
\text { apps marketed by the developer of the given app in } \\
\text { the given week in the specific store. }\end{array}$} \\
\hline \multicolumn{2}{|l|}{ Price (dependent variable) } & \multicolumn{2}{|c|}{$\begin{array}{l}\text { Continuous variable measuring the price (in Euros) } \\
\text { of the app in the given week. }\end{array}$} \\
\hline \multicolumn{2}{|c|}{$\begin{array}{l}\text { Store (Google Play; App Store; Blackberry } \\
\text { World) }\end{array}$} & \multicolumn{2}{|c|}{$\begin{array}{l}\text { Three binary variables, each equal to } 1 \text { if, in the } \\
\text { given week, the app is available for download in the } \\
\text { respective store; } 0 \text { otherwise. }\end{array}$} \\
\hline \multicolumn{2}{|l|}{ Total apps } & \multicolumn{2}{|c|}{$\begin{array}{l}\text { Total number of apps downloadable from the given } \\
\text { store in the given week. }\end{array}$} \\
\hline \multicolumn{2}{|l|}{ Two-sided market effect } & \multicolumn{2}{|c|}{$\begin{array}{l}\text { Binary variable equal to } 1 \text { if the developer utilises a } \\
\text { two-sided market business model for the app (e.g., } \\
\text { enjoys revenue from advertisers in addition to } \\
\text { selling to final users) in the given week; } 0 \text { otherwise. }\end{array}$} \\
\hline \multicolumn{2}{|l|}{ First version } & \multicolumn{2}{|c|}{$\begin{array}{l}\text { Binary variable equal to } 1 \text { if, at the given week, the } \\
\text { app is released in the first version, } 0 \text { if it is released } \\
\text { in subsequent version. }\end{array}$} \\
\hline \multicolumn{2}{|l|}{ Free trial version } & \multicolumn{2}{|c|}{$\begin{array}{l}\text { Binary variable equal to } 1 \text { if a free trial version for } \\
\text { the app is available in the given week; } 0 \text { otherwise. }\end{array}$} \\
\hline \multicolumn{2}{|l|}{ Free version } & \multicolumn{2}{|c|}{$\begin{array}{l}\text { Binary variable equal to } 1 \text { if a free version for the } \\
\text { app is available in the given week; } 0 \text { otherwise. }\end{array}$} \\
\hline \multicolumn{4}{|c|}{ Table 2 Descriptive statistics } \\
\hline Variables & Descr. stat. & Variables & Descr. stat. \\
\hline Binary variables & $\% 1$ & Binary variables & $\% 1$ \\
\hline Google play & $33.33 \%(23.17 \%)$ & Education & $0.49 \%(0.95 \%)$ \\
\hline App store & $33.33 \%(41.59 \%)$ & Fun and entertainment & $6.08 \%(6.35 \%)$ \\
\hline Blackberry world & $33.33 \%(35.24 \%)$ & Games & $35.2 \%(40 \%)$ \\
\hline Two-sided market effect & $19.51 \%(11.11 \%)$ & Healthcare and fitness & $0.59 \%(1.59 \%)$ \\
\hline
\end{tabular}

Notes: The values outside the parentheses are computed at the observation level, whereas the values inside the parentheses are computed at the app level. However, for developer fame, developer type, and number developer apps the values inside the parentheses are computed at the developer level (the total number of developers is 227), whereas for app size and first version they are computed at the app version level (the total number of different versions is 487). As for the developer rating dummies, the statistics are computed considering only the total observations because the rating may not only vary within the 34 weeks period but also among different apps of the same developer due to the fact that for each app we omit the relative rating to avoid a reverse causality problem. 
Table 2 Descriptive statistics (continued)

\begin{tabular}{|c|c|c|c|c|}
\hline Variables & Descr. stat. & \multicolumn{2}{|c|}{ Variables } & Descr. stat. \\
\hline Free trial version & $23.63 \%(19.37 \%$ & \multicolumn{2}{|c|}{ Money and finance } & $0.49 \%(1.27 \%)$ \\
\hline Free version & $21.76 \%(11.95 \%)$ & \multicolumn{2}{|c|}{ Music } & $6.27 \%(4.13 \%)$ \\
\hline In-app purchase & $17.06 \%(17.14 \%)$ & \multicolumn{2}{|c|}{ Transportation } & $0.98 \%(1.9 \%)$ \\
\hline First version & $12.94 \%(13.96 \%)$ & \multicolumn{2}{|c|}{ News and info } & $1.08 \%(2.86 \%)$ \\
\hline Developer fame & $8.14 \%(5.29 \%)$ & \multicolumn{2}{|c|}{ Photo and video } & $4.71 \%(6.98 \%)$ \\
\hline No developer rating & \multicolumn{3}{|c|}{ Social network } & $4.12 \%(1.27 \%)$ \\
\hline Low developer rating & \multicolumn{3}{|c|}{ Themes and customisation } & $12.35 \%(12.06 \%)$ \\
\hline Medium developer rating & \multicolumn{3}{|c|}{ Utility } & $27.65 \%(20.63 \%)$ \\
\hline High developer rating & $60.59 \%$ & \multicolumn{2}{|c|}{ Developer type } & $82.45 \%(66.96 \%)$ \\
\hline Variables & \multicolumn{4}{|c|}{ Descriptive statistics } \\
\hline Continuous/discrete & Mean & Std.D. & Min & $\operatorname{Max}$ \\
\hline App size (Mbyte) & $32.876(39.172)$ & $131.303(138.666)$ & 0.02 & 1100 \\
\hline Number developer apps & $28.916(27.914)$ & $48.376(47.327)$ & 1 & 313 \\
\hline Total apps & 256,735 & 175,996 & 29,721 & 542,446 \\
\hline Google Play & 267,181 & 51,070 & 180,616 & 346,782 \\
\hline App Store & 461,135 & 46,355 & 386,327 & 542,446 \\
\hline Blackberry World & 41,891 & 6,611 & 29,721 & 52,376 \\
\hline Price $(€)$ & 1.94 & 2.11 & 0.1 & 10.99 \\
\hline
\end{tabular}

Note: The values outside the parentheses are computed at the observation level, whereas the values inside the parentheses are computed at the app level. However, for developer fame, developer type, and number developer apps the values inside the parentheses are computed at the developer level (the total number of developers is 227), whereas for app size and first version they are computed at the app version level (the total number of different versions is 487). As for the developer rating dummies, the statistics are computed considering only the total observations because the rating may not only vary within the 34 weeks period but also among different apps of the same developer due to the fact that for each app we omit the relative rating to avoid a reverse causality problem.

First of all, the price (in Euros) of the given app observed every Friday in one of the three store rankings is the dependent variable. To test the two-sided market effect, with no access to revenue information from third parties, e.g., advertisers, we analyse each app to check for the presence of ads inside the app. We also check whether the business model of each app is explicitly centred on gathering and selling (non-personally identifiable) data of a large user-base. Apps containing ads or supporting collection and sale of large amount of data operate as two-sided markets. Thus, we define a dummy variable (two-sided market effect) indicating whether the given app operates as a two-sided market or not. To test the effect of trialability $(H 2)$ we retrieve information on the existence of a proper free trial version for the app and introduce a dummy (free trial version) to measure the effect of trialability. As discussed earlier, we distinguish between proper free trial version, i.e., version offering very limited features or being time-locked, and free version, i.e., version that do not differ much from the paid version except for the presence of ads. We control for the effect of free versions including a specific variable (free version). We test $H 3$ simply introducing a dummy variable (in-app purchase), which 
indicates whether in-app purchase is implemented for the given paid app, or not. Collecting data about the specific version of each app also enables us to test whether price skimming or penetration price strategies are adopted. Therefore, we introduce a dummy (first version) indicating whether the first or a subsequent version is observed for each app. Finally, we consider the role of online mechanisms to build reputation on app price (H5). Usually, app stores allow users to provide apps' rating on a 1-to-5 scale where 1 corresponds to the worst valuation and 5 to excellent valuation ${ }^{5}$. However, no developer rating is available in the major distribution platforms, although in each store users can visualise the developer page with all the apps and the relative ratings. Therefore, to study the effect of these mechanisms, we construct a measure of developer's current rating by computing the average ratings of all the apps marketed in the given store by the given content provider until the given week. In order to avoid any reverse causality problem, which might create endogeneity in the regression model, for each app we exclude the rating of the app itself when computing the average rating ${ }^{6}$. Also, sometimes no rating can be computed for some developers because the number of users who have provided a rating is too low (the threshold is determined by the specific app store) or no other apps have been marketed ${ }^{7}$. To cope with this issue, we construct three dummies based on the average rating: low rated developers (low developer rating) category if the average developer rating is below 2.5, medium rated developers (medium developer rating) category if the average developer rating is between 2.5 and 3.5 and high rated developers (high developer rating) category if the average developer rating is above 3.5. By doing so, we can compare the effect of low, medium and high developer ratings with respect to the absence of developer rating. Regarding the effect of reputation, we also include a dummy (developer fame), which indicates whether the developer/brand of the given app is one of those giant developers/brand reported in Table 1, who have a fully established reputation worldwide.

Furthermore, we include some control variables, such as the app store (App Store, Google Play, Blackberry World), the app category (we count 12 different categories in our sample ${ }^{8}$ ), the type of developer (developer type), i.e., whether the content provider is a firm or (group of) individual(s), the number of apps marketed by each developer (number developer apps) in the given week and store, and the app size in megabyte (app size). Finally, we include a temporal dummy ( $w_{e} e k_{t}$ ) for every Friday to control for any other potential cause of price change in specific weeks 9 .

In addition to some dummies chosen as baseline variables due to perfect collinearity $^{10}$, our preliminary analysis suggests that the variable medium developer Rating shows a serious degree of negative correlation with the variable high developer Rating (the Pearson correlation index is about -0.76 ). We remove medium developer Rating, as we are more interested in the effect of high developer rating on prices. After removing such variables we observe no further serious degree of collinearity.

\subsection{Empirical results}

In our regression model, we use a log-linear functional form, where the log-price is regressed against explanatory and control variables. Such functional form has been shown to be effective for hedonic price estimation (Gandal, 1994; Brynjolfsson and Kemerer, 1996; Gallaugher and Wang, 2002; Roma et al., 2013) and in other related pricing studies (e.g., Roma et al., 2014, 2015). When the number of statistical units is quite large compared to the observation period (number of weeks), three basic regression 
models, namely pooled OLS, fixed effects and random effects models, are usually suggested (Wooldridge, 2002). However, the fixed effects model is not appropriate in our setting because some variables of interest, e.g., the distribution platform, are time invariant. Therefore, we preliminarily compare pooled OLS and random effects models. The Breusch-Pagan Lagrange Multiplier test strongly indicates the presence of random effects, as highlighted below Table 3 , where the results under the random effects model are illustrated. For sake of parsimony, we use a stepwise procedure to eliminate the least relevant variables. We gradually delete the least significant variable and stop when the estimated coefficients are significant at least at the $10 \%$ level. The results of the restricted model are also presented in Table 3. We also report the F-test, which suggests that the full model does not provide any significant better fit than the restricted one. Due to very high similarities between full and restricted models, we only comment the restricted model. Before discussing the results of our formulated hypotheses, it is worthwhile to mention that, among the control variables, numerous, but not all, app categories, e.g., utility, music, money and finance, social networks, news and info, show significantly higher prices compared to the category games. Other categories, such as customisation and themes and photo and video, are shown to be not significant. This expected result could be attributed to the fact that different categories have different nature in terms of customer targets and/or needs. The type of developer and app size are also significant in explaining price formation. Specifically, firms enjoy higher prices than individual developers. This is intuitive because software houses are likely to have better development and marketing capabilities and a higher knowledge of the market, which possibly result in higher quality apps and a better exploitation of the market potential. It is also quite straightforward that, given that we control for the effect of different app categories, the conditional effect of the app size on price is positive as a higher size roughly reflects a higher complexity to respond to more sophisticated consumer targets and/or needs. Finally, only two temporal dummies have positive impact on price. Thus, no particular unobserved factors that we tried to capture introducing temporal dummies seem to be influential.

Moving to major results, our first hypothesis is supported by empirical evidence. Top paid apps containing ads or supporting collection and sale of large amount of data show significantly lower prices. This suggests that apps have properties of two-sided markets. Specifically, the lower prices charged for apps showing such properties are the evidence of the subsidy provided by developers to end users as a consequence of the strong positive cross-side externalities exerted by them on valuable third parties, e.g., advertisers. In fact, as expected, third parties value end users, when attracted in mass, much more than end users value third parties. Managers and app developers may take advantage of our findings. In fact, lowering the price to the mass of end users to attract those third parties from which to profit abundantly. When, for instance, the presence of ads significantly increase to become a hassle, end users might even suffer from negative externalities. In this case, the subsidy might be so large to lead to the 'free plus ads' business model widely adopted in the app market. 
Table 3 Random effects regression results under full and restricted models

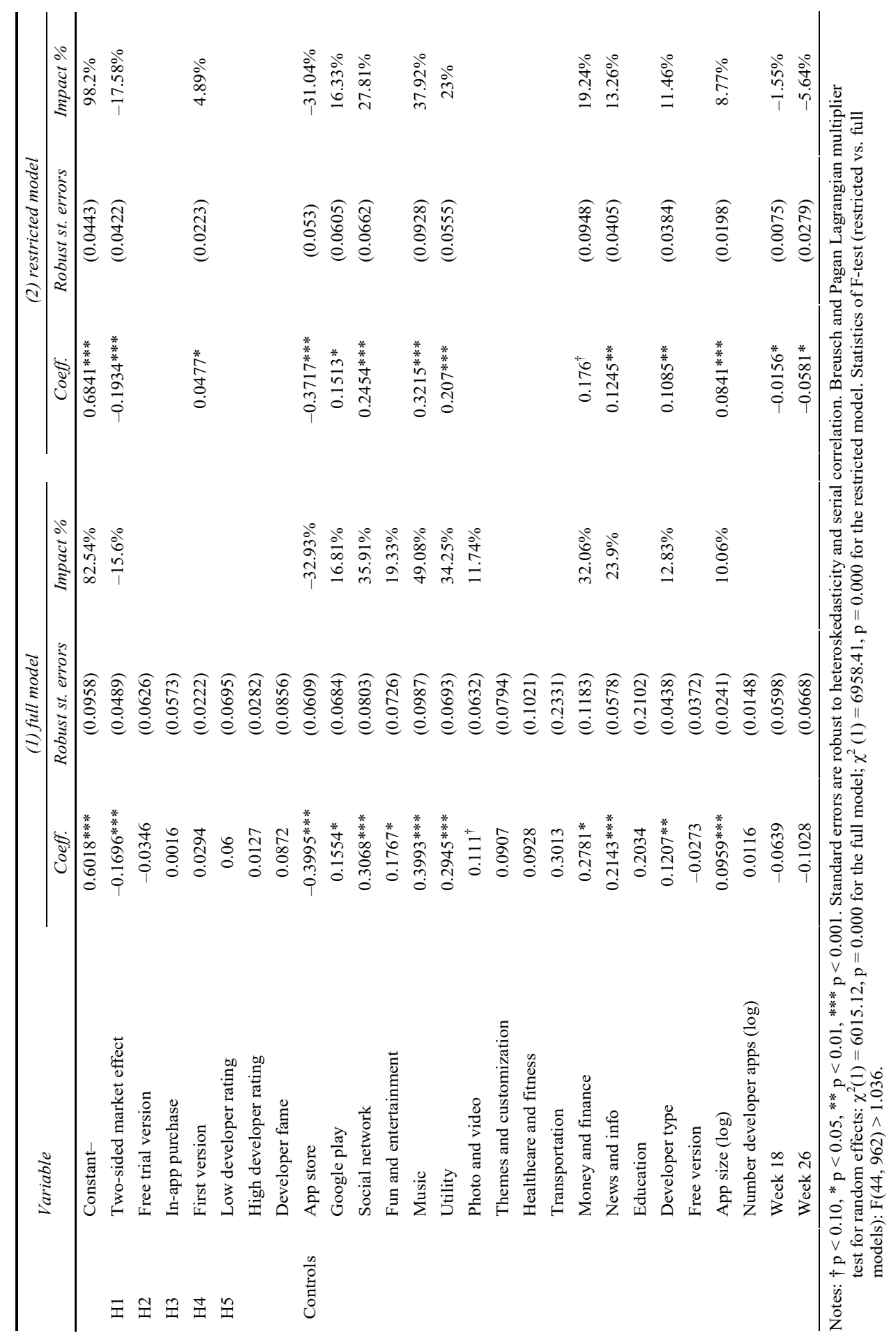


Table 3 Random effects regression results under full and restricted models (continued)

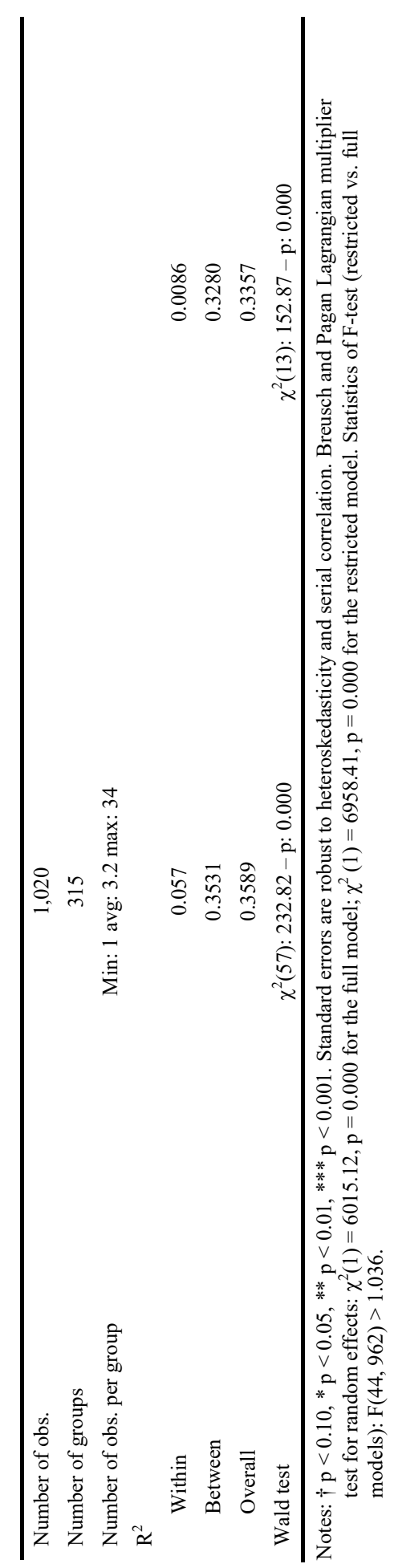


Our empirical analysis provides an interesting result regarding hypothesis $H 2$. In our sample, the effect of the free trial version on app price is shown to be not significant. Essentially, there is no evidence that top paid apps for which free trial versions are available are sold at a higher price compared to top paid apps for which a free trial version is not released. This happens even after distinguishing between free trial version and free version. Recall that this distinction helps remove the possible risk of demand cannibalisation for paid apps and focus only on the role of proper free trial versions, i.e., those versions designed only with the scope to reduce asymmetry and help consumers discover the real value of a product to them. Therefore, the result suggests that, in case of top paid apps, consumers do not recognise any price premium to developers who introduce a free trial version. This is because consumers possibly perceive free trial versions as something useful to evaluate whether to make the purchase or not, rather than a vehicle to increase their willingness to pay. After all, they face low risks associated with the uncertainty about the product value due to the relatively low prices of top paid apps. In addition, perhaps, the fact that an app is in the top ten ranking is itself a strong signal of quality, which may cancel the positive effect of the free trial version on price. However, it is worthwhile to point out that, even with no impact on price, the presence of a free trial version might still have positive effects on the revenue developers can earn from the corresponding paid app due to the positive effect on sales.

Similarly to the effect of trialability, the effect of in-app purchase on app price is shown to be not significant. Developers giving consumers the opportunity to make in-app purchases do not reduce the price of the base version, as theory would suggest. In fact, in-app purchase does not determine any price difference in our sample of successful paid apps. This is possibly explained by the strong consumer reluctance to buy further upgrades after having already paid for the base version, which, in turn, induces developers to raise the price level to prevent revenue losses. Numerous recent industry reports assert that in-app purchase has become amazingly popular among app users (Spriensma, 2012). While, this might appear in contrast with our result, there is actually no contrast as the acclaimed success of in-app purchase is related to free apps, certainly not to paid apps. As a matter of fact, analytics company Apsalar explains that in-app purchases are viewed by consumers as substitutes of paid apps, in the sense that in-app purchases are not attractive to consumers if they have already paid for an app (Apsalar, 2012). Therefore, our result on the role of in-app purchase seems to be consistent with industry feedbacks.

As for the effect of the initial version, hypothesis $H 4 b$ is confirmed, although only when the reduced model is considered. Apps first released show higher prices than apps available in subsequent versions, ceteris paribus. This seems to suggest that app developers favour a price skimming strategy rather than a penetration strategy. Based on theory, this implies the existence of a market with high customer heterogeneity that developers can profitably segment extracting surplus from valuable users first. In case of top paid apps, the benefits derived taking advantage from such customer heterogeneity seem to prevail over those developers could obtain setting low introductory prices and exploiting network externalities among users. Interestingly, this result adds to the result on the effect of trialability, possibly subtracting support to the argument that network externalities have a role in app price formation as prominent as that in other software markets. As a matter of fact, under both cases, we do not observe evidence of particularly strong network externalities among users. 
Finally, a further surprising result is related to the effect of online mechanisms to build reputation. Consistent with most of the literature, we would have expected a positive impact of such mechanisms. However, we find no empirical evidence of the role of online reputation mechanisms, in line with a minority of studies. In fact, in case of top paid apps, data seem to suggest that developers of apps with high ratings on average are not guaranteed to enjoy price premiums. Also, low ratings or absence of ratings do not affect price negatively. The negligible effect of online reputation mechanisms in the context of successful apps might be explained by the substitutable role of ratings and top rankings as mechanisms to signal quality in presence of product/seller uncertainty. The fact that an app ranks among top ten apps represents itself a sort of guarantee to consumers, which might make the role of ratings irrelevant. Interestingly, our results also show that no price premiums are reserved to developers with a fully established reputation worldwide. Therefore, our analysis suggests that reputation is not likely to play a crucial role in determining prices at least when top paid apps are considered. To ascertain whether reputation has a relevant role in price formation on a more general level, apps should be observed from the very early stages of market introduction until they steadily reach top ranks. The study of apps along their lifecycle can be a promising research direction. The summary of our findings and the relative explanations are provided in Table 4.

Table 4 Summary of the findings

\begin{tabular}{|c|c|c|c|}
\hline \multicolumn{2}{|c|}{ Variables } & \multirow{2}{*}{$\frac{\text { Status }}{\text { Confirmed }}$} & \multirow{2}{*}{$\begin{array}{l}\text { Motivation } \\
\text { Developers of apps operating as two-sided } \\
\text { markets are confirmed to strategically reduce the } \\
\text { price to end users as they can count on the } \\
\text { positive externalities they exert on third parties, } \\
\text { e.g., advertisers. }\end{array}$} \\
\hline H1 & $\begin{array}{l}\text { Two-sided market } \\
\text { effect }\end{array}$ & & \\
\hline $\mathrm{H} 2$ & Trialability effect & Not confirmed & $\begin{array}{l}\text { The fact that the effect of trialability is not } \\
\text { significant in the context of successful apps is } \\
\text { possibly explained by the low risks consumers } \\
\text { perceive relatively to the uncertainty on product } \\
\text { value as top paid apps have low prices and are } \\
\text { already in a top ranking. }\end{array}$ \\
\hline H3 & $\begin{array}{l}\text { In-app purchase } \\
\text { effect }\end{array}$ & Not confirmed & $\begin{array}{l}\text { The non-significance of the in-app purchase effect } \\
\text { for paid apps can be explained by due to } \\
\text { consumers' reluctance to additional payments. }\end{array}$ \\
\hline H4 & $\begin{array}{l}\text { Introductory pricing } \\
\text { policy effect }\end{array}$ & Confirmed & $\begin{array}{l}\text { The analysis provides slightly evidence that } \\
\text { developers adopt price skimming strategy } \\
\text { possibly because the customer heterogeneity in } \\
\text { terms of willingness to pay is a more relevant } \\
\text { issue as compared with the effect of network } \\
\text { externalities in the context of paid apps. }\end{array}$ \\
\hline H5 & Reputation effect & Not confirmed & $\begin{array}{l}\text { The non-significance of the reputation variables is } \\
\text { likely to be due to the fact that the persistent } \\
\text { presence in the top paid ranking is already a } \\
\text { mechanism to signal long-term quality. }\end{array}$ \\
\hline
\end{tabular}




\section{Conclusions}

\subsection{Managerial implications}

Since the App Store introduction, mobile apps commerce has grown exponentially, and numerous researches predict an even rosier future in the next years. This rapid growth of the app market offers numerous business opportunities to a multitude of developers. It also offers a great opportunity for researchers to examine various theoretical and/or methodological issues. However, despite the great popularity the mobile app market has reached, the academic study of this market has just started. In this paper, we construct a hedonic price model and test a number of hypotheses to examine the role of relevant factors in price formation in the app market. Specifically, we investigate price formation based on a sample of top paid apps for smartphones from the Italian version of the major app stores, namely App Store, Google Play and Blackberry World.

Based on our results we can make several remarkable points. The negative relationship between the two-sided market dummy and the app price provides the first empirical evidence in the software market of how the adoption of a two-sided market business model can modify the price charged to consumers. This is because developers of apps operating as two-sided markets strategically reduce the price to end users as they can count on the positive externalities they exert on the opposite side, e.g., advertisers. In this case, developers make profits from these more valuable third parties.

Second, most of previous empirical studies show that there exist positive effects of trialability and online mechanisms to build reputation on product price. In contrast, our results suggest that such positive influences might not be in place in the context of successful apps. As for the role of trialability, this is possibly explained by the low risks consumers perceive relatively to the uncertainty on product value as top paid apps have low prices. Therefore, while trialability might still important to induce consumers' purchases, developers who release free trial versions should not expect to extract a higher surplus from top paid app users. As for the role of online mechanisms to build reputation, the argument that sellers can enjoy price premiums as a return of high ratings is not supported at least for top paid apps. This is possibly because in consumers' mind the presence of an app among top apps is already a guarantee of quality. Therefore, while it would be interesting to study the effect of reputation mechanisms along the entire app lifecycle, our result poses a question on the actual effectiveness of app ratings to generate reputation benefits in a context where consumers are induced to visualise only apps appearing in top rankings. Our finding implies that, at least for top paid apps, developers should not care much about the rating mechanisms provided by the app stores. Another implication is related to app store owners who might reconsider and revamp the logic behind providing these ratings in order to make them more impactful at least with regard to top paid apps.

Third, we find no evidence that apps allowing in-app purchase are associated with lower prices. This result actually seems to support previous arguments on the non-optimality of versioning information goods found under numerous settings. It is also consistent with some industry reports pointing out that consumers consider in-app purchases as economic substitutes of paid apps. By maintaining prices as high as those of developers who do not offer the in-app purchase option, developers offering this opportunity seem to protect themselves from revenue losses due to consumers' reluctance to additional payments. Thus, our result would imply reconsidering the suitability of the 
in-app purchase model for paid apps. In fact, our suggestion to developers is in fact that they should avoid opting for in-app purchase if they have chosen a paid app strategy.

Finally, our finding that initial versions are associated with higher prices seems to demonstrate a slight prevalence of price skimming strategy over price penetration. This might implicitly indicate the existence of a high consumers' heterogeneity in terms of willingness to pay, which more than outweighs the effect of intra-network externalities. Therefore, although evidence is provided using an indirect measure of the intra-network externalities effect (i.e., our variable first version), an interesting implication is that network externalities in the app market might not have a role as prominent as they do in other information goods markets and thus in general developer should tend to adopt a price skimming strategy. In fact, marketing theory suggests that, everything else equal, firms should opt for price skimming strategy over price penetration strategy when network externalities are not very relevant as compared to consumers' heterogeneity in terms of willingness to pay (Dean, 1969; Tellis, 1986; Noble and Gruca, 1999).

\subsection{Research limitations and future research}

To the best of our knowledge this is one of the very first studies focusing on the app market, and the first study examining the role of relevant factors in price formation in the app market. Therefore, there are some natural limitations, which could be overcome in future works. First, although we extended the period of observation compared to previous works on the app market, the present study is constrained by the time period. Perhaps, due to the turbulences typical of new and fast growing markets, results may change over time if competition and demand conditions vary. However, most of the results we obtain seem to be either consistent with preceding literature, e.g., the two-sided effect, or supported by reports from industry experts, e.g., the role of distribution platform or in-app purchase. Second, data are restricted to top ten paid apps. While this helps reduce the collection effort required by the extensive amount of data, an analysis using a larger number of ranked apps at the expense of a shorter observation period would certainly complement the present study. As noted earlier, a possible disadvantage of this kind of analysis might be the absence of a significant increase in the number of apps due to the low variability that can be found, especially in the first ranks, in a short time period. Also, many variables of interest, e.g., the price, might not change if the time period is short, resulting in duplications of the same information.

Echoing Garg and Telang (2013), we expect that many researchers will devote themselves to the study of this market. There is a wide spectrum of possible research directions besides the above extensions. For instance, a promising direction may be the study of distribution platform competition. The app distribution model is more than a simple two-sided market due to the presence of numerous business interactions. As a result, numerous relevant issues, such as new product or alliance decisions in competitive environments (Lo Nigro et al., 2013), should be investigated taking into account the network structure and the existing interactions. 


\section{References}

Agarwal, R. and Prasad, J. (1997) 'The role of innovation characteristics and perceived voluntariness in the acceptance of information technologies', Decision Sciences, Vol. 28, No. 3, pp.557-582.

Apsalar, A.P. (2012) What Types of Users Make the Most In-app Purchases? Study Highlights Key Predictors [online] http://apsalar.com/blog/2012/09/what-types-of-users-make-the-most-inapp-purchases-study-highlights-key-predictors/ (accessed 11 February 2015).

Armstrong, M. (2006) 'Competition in two-sided markets', RAND Journal of Economics, Vol. 37, No. 3, pp. 668-691.

Ba, S. and Pavlou, P.A. (2002) 'Evidence of the effect of trust building technology in electronic markets: price premiums and buyer behavior', MIS Quarterly, Vol. 26, No. 3, pp.243-268.

Bajari, P. and Hortacsu, A. (2003) 'Winner's curse, reserve prices and endogenous entry: empirical insights from eBay auctions', RAND Journal of Economics Vol. 34 No. 2, pp. 329-355.

Banerjee, A.V. and Duflo, E. (2000) 'Reputation effects and the limits of contracting: a study of the Indian software industry', The Quarterly Journal of Economics, Vol. 115, No. 3, pp.989-1017.

Bawa, K. and Shoemaker, R. (2004) 'Effects of free sample promotions on incremental brand sales', Marketing Science, Vol. 23, No. 3, pp.345-363.

Beard, C. and Easingwood, C. (1996) 'New product launch: marketing action and launch tactics for high-technology products', Journal of Marketing Management, Vol. 25, No. 2, pp.87-103.

Berndt, E. (1991) The Practice of Econometrics, Classic and Contemporary, Addison-Wesley, Reading.

Bhargava, H.K. and Choudhary, V. (2001) 'Information goods and vertical differentiation', Journal of Management Information Systems, Vol. 18, No. 2, pp.89-106.

Bhargava, H.K. and Choudhary, V. (2008) 'When is versioning optimal for information goods?', Management Science, Vol. 54, No. 5, pp.1029-1035.

Bolton, G.E., Katok, E. and Ockenfels, A. (2004) 'How effective are electronic reputation mechanisms? An experimental investigation', Management Science, Vol. 50, No. 11, pp.1587-1602.

Brynjolfsson, E. and Kemerer, C.F. (1996) 'Network externalities in microcomputer software: an econometric analysis of the spreadsheet market', Management Science, Vol. 42, No. 12, pp.1627-1647.

Canalys (2012) Android Apps are Too Expensive, February 23 [online] $\mathrm{http}: / /$ www.canalys.com/newsroom/android-apps-are-too-expensive (accessed 11 February 2015).

Carare, O. (2012) 'The impact of bestseller rank on demand: evidence from the app market', International Economic Review, Vol. 53, No. 3, pp.717-742.

Chatterjee, R. (2009) 'Strategic pricing of new products and services', in Rao, V.R. (Ed.): Handbook of Pricing Research in Marketing, pp.169-215, Edward Elgar Publishing Limited, Cheltenham.

Chen, R.R., Gal-Or, E. and Roma, P. (2014) 'Opaque distribution channels for competing service providers: posted price vs. name-your-own-price mechanisms', Operations Research, Vol. 62, No. 4, pp.733-750.

Cheng, H.K. and Liu, Y. (2012) 'Optimal software free trial strategy: the impact of network externalities and consumer uncertainty', Information Systems Research, Vol. 23, No. 2, pp.488-504.

Cheng, H.K. and Tang, Q.C. (2010) 'Free trial or no free trial: optimal software product design with network effects', European Journal of Operational Research, Vol. 205, No. 2, pp.437-447.

Chow, G.C. (1967) 'Technological change and the demand for computers', The American Economic Review, Vol. 57, No. 7, pp.1117-1130. 
Dean, J. (1950) 'Pricing policies for new products', Harvard Business Review, Vol. 28, No. 6, pp.45-53.

Dean, J. (1969) 'Pricing pioneering products', The Journal of Industrial Economics, Vol. 17, No. 3, pp.165-179.

Dellarocas, C. (2003) 'The digitization of word of mouth: promise and challenges of online feedback mechanisms', Management Science, Vol. 49, No. 10, pp.1407-1424.

Dimoka, A., Hong, Y. and Pavlou, P.A. (2012) 'On product uncertainty in online markets: theory and evidence', MIS Quarterly, Vol. 36, No. 10, pp.395-426.

Dolan, R.J. and Jeuland, A.P. (1981) 'Experience curves and dynamic demand models: implications for optimal pricing strategies', Journal of Marketing, Vol. 45, No. 1, pp.52-62.

Dubé, J-P. H., Hitsch, G.J. and Chintagunta, P.K. (2010) 'Tipping and concentration in markets with indirect network effects', Marketing Science, Vol. 29, No. 2, pp.216-249.

Eisenmann, T., Parker, G. and van Alstyne, M.W. (2006) 'Strategies for two-sided markets', Harvard Business Review, Vol. 84, No. 10, pp.1-11.

Evans, D.S. (2003) 'Some empirical aspects of multi-sided platform industries', Review of Network Economics, Vol. 2, No. 3, pp.191-209.

Farago, P. (2012) The Great Distribution of Wealth Across iOS and Android Apps, July 31 [online] http://blog.flurry.com/bid/88014/The-Great-Distribution-of-Wealth-Across-iOS-and-AndroidApps (accessed 11 February 2015).

Gallaugher, J.M. and Wang, Y. (2002) 'Understanding network effects in software markets: evidence from web server pricing', MIS Quarterly, Vol. 26, No. 4, pp.303-327.

Gandal, N. (1994) 'Hedonic price indexes for spreadsheets and an empirical test for network externalities', RAND Journal of Economics, Vol. 25, No. 1, pp.160-170.

Gandal, N. (1995) 'Competing compatibility standards and network externalities in the PC software market', The Review of Economics and Statistics, Vol. 77, No. 4, pp.599-608.

Garg, R. and Telang, R. (2013) 'Inferring app demand from publicly available data', MIS Quarterly, Vol. 37, No. 4, pp.1253-1264.

Gartner (2013) Gartner Says Mobile App Stores will See Annual Downloads Reach 102 Billion in 2013, 19 September [online] http://www.gartner.com/newsroom/id/2592315 (accessed 11 March 2015).

Ghezzi, A., Balocco, R. and Rangone, A. (2010) 'How a new distribution paradigm changes the core resources, competences and capabilities endowment: the case of mobile application stores', ICMB '10: Proceedings of the 9th International Conference on Mobile Business, pp.33-42, IEEE Computer Society, Washington, DC.

Ghose, A. and Han, S.P. (2014) 'Estimating demand for mobile applications in the new economy', Management Science, Vol. 60, No. 6, pp.1470-1488.

Goering, P.A. (1985) 'Effects of product trial on consumer expectations, demand, and prices', Journal of Consumer Research, Vol. 12, No. 1, pp.74-82.

Houser, D. and Wooders, J. (2006) 'Reputation in auctions: theory, and evidence from eBay', Journal of Economics \& Management Strategy, Vol. 15, No. 2, pp.353-369.

Kaiser, U. and Wright, J. (2006) 'Price structure in two-sided markets: evidence from the magazine industry', International Journal of Industrial Organization, Vol. 24, No. 1, pp.1-28.

Kalish, S. (1983) 'Monopolist pricing with dynamic demand and production cost', Marketing Science, Vol. 2, No. 2, pp.135-159.

Kauffman, R.J. and Wood, C.A. (2006) 'Doing their bidding: an empirical examination of factors that affect a buyer's utility in internet auctions', Information Technology and Management, Vol. 7, No. 3, pp.171-190.

Keynote Competitive Research (2012) 2012 Mobile User Survey, Keynote Competitive Research Report [online] http://www.keynote.com (accessed 11 February 2015).

Khalaf, S. (2012) Mobile Apps: We Interrupt This Broadcast, 5 December [online] http://blog.flurry.com/default.aspx?Tag=Television (accessed 11 February 2015). 
Klein, B. and Leffler, K.B. (1981) 'The role of market forces in assuring contractual performance', Journal of Political Economy, Vol. 89, No. 4, pp.615-641.

Kuo, Y. and Yu, C. (2006) '3G telecommunication operators' challenges and roles: a perspective of mobile commerce value chain', Technovation, Vol. 26, No. 12, pp.1347-1356.

Lee, Y. and Colarelli O'Connor, G. (2003) 'New product launch strategy for network effects products', Journal of the Academy of Marketing Science, Vol. 31, No. 3, pp.241-255.

Liu, H. (2010) 'Dynamics of pricing in the video game console market: skimming or penetration?', Journal of Marketing Research, Vol. 47, No. 3, pp.428-443.

Livingston, J.A. (2005) 'How valuable is a good reputation? a sample selection model of internet auctions', The Review of Economics and Statistics, Vol. 87, No. 3, pp.453-465.

Lo Nigro, G., Morreale, A., Robba, S. and Roma, P. (2013) 'Biopharmaceutical alliances and competition: a real options game approach', International Journal of Innovation Management, Vol. 17, No. 6, p.1340023.

Lucking-Reiley, D., Bryan, D., Prasad, N. and Reeves, D. (2007) 'Pennies from eBay: the determinants of price in online auctions', The Journal of Industrial Economics, Vol. 55, No. 2, pp.659-680.

Lunden, I. (2013) Gartner 102B App Store Downloads Globally in 2013, \$26B in Sales, 17\% from In-App Purchases, September 19 [online] http://techcrunch.com/2013/09/19/gartner-102bapp-store-downloads-globally-in-2013-26b-in-sales-17-from-in-app-purchases/ (accessed 11 February 2015).

Mahajan, V., Muller, E. and Bass, F.M. (1990) 'New product diffusion models in marketing: a review and directions for research', Journal of Marketing, Vol. 54, No. 1, pp.1-26.

Melnik, M. and Alm, J. (2002) 'Does a seller's ecommerce reputation matter? Evidence from eBay auctions', The Journal of Industrial Economics, Vol. 50, No. 3, pp.337-349.

Moore, G.C. and Benbasat, I. (1991) 'Development of an instrument to measure the perceptions of adopting an information technology innovation', Information Systems Research, Vol. 2, No. 3 , pp.192-222.

Nascimento, F. and Vanhonacker, W.R. (1988) 'Optimal strategic pricing of reproducible consumer products', Management Science, Vol. 34, No. 8, pp.921-937.

Nielsen (2012) Social Media Report 2012: Social Media Comes of Age, August [online] http://www.nielsen.com/us/en/newswire/2012/social-media-report-2012-social-media-comesof-age.html (accessed 11 February 2015).

Noble, P.M. and Gruca, T.S. (1999) 'Industrial pricing: theory and practice', Marketing Science Vol. 18, No. 3, pp.435-454.

Palumbo, F. and Dominici, G. (2015) 'Unraveling the complexity of tourist experience with NFC technology and mobile wallets', in Erçetin, S.S. and Banerjee, S. (Eds.): Chaos, Complexity and Leadership 2013, pp.189-196, Springer Proceedings in Complexity, Springer.

Palumbo, F., Dominici, G. and Basile, G. (2014) 'The culture on the palm of your hand: how to design a user oriented mobile app for museums' in management of cultural products', in Aiello, L. (Ed.): Handbook of Research on Management of Cultural Products: E-Relationship Marketing and Accessibility Perspectives, pp.224-243, IGI Global, Hershey, Pennsylvania, USA.

Parker, G. and van Alstyne, M. (2005) 'Two-sided network effects: a theory of information product design', Management Science, Vol. 51, No. 10, pp.1494-1504.

Pavlou, P. and Dimoka, A. (2006) 'The nature and role of feedback text comments in online marketplaces: implications for trust building, price premiums, and seller differentiation', Information Systems Research, Vol. 17, No. 4, pp.392-414.

Resnick, P. and Zeckhauser, R. (2002) 'Trust among strangers in internet transactions: empirical analysis of ebay' s reputation system', in Baye, M.R. (Ed.): The Economics of the Internet and E-commerce (Advances in Applied Microeconomics, Volume 11), pp.127-157, Elsevier Science, Amsterdam. 
Resnick, P., Zeckhauser, R., Swanson, J. and Lockwood, K. (2006) 'The value of reputation on eBay: a controlled experiment', Experimental Economics, Vol. 9, No. 2, pp.79-101.

Robinson, B. and Lakhani, C. (1975) 'Dynamic price models for new product planning', Management Science, Vol. 21, No. 10, pp.1113-1122.

Rocha, E. (2012) RIM to Spice Blackberry 10 AppWorld with Local Flavors, 15 November [online] http://www.reuters.com/article/2012/11/16/us-rim-blackberry-idUSBRE8AD1P520121116 (accessed 11 February 2015).

Rochet, J.C. and Tirole, J. (2003) 'Platform competition in two sided markets', Journal of the European Economic Association, Vol. 1, No. 4, pp.990-1029.

Rochet, J.C. and Tirole, J. (2006) 'Two sided markets: a progress report', RAND Journal of Economics, Vol. 37, No. 3, pp.645-667.

Rogers, E.M. (1983) Diffusion of Innovations, Free Press, New York.

Roma, P., Di Martino, G. and Perrone, G. (2013) 'What to show on the wine labels: a hedonic analysis of price drivers of Sicilian wines', Applied Economics, Vol. 45, No. 19, pp.2765-2778.

Roma, P., Zambuto, F. and Perrone, G. (2014) 'Price dispersion, competition, and the role of online travel agents: evidence from business routes in the Italian airline market', Transportation Research Part E, Vol. 69, No. C, pp.146-159.

Roma, P., Zambuto, F. and Dominici, G. (2015) 'An empirical analysis of online price dispersion in the Italian airline industry', International Journal of Electronic Marketing and Retailing, Vol. 6, No. 4, pp.339-358.

Rosen, S. (1974) 'Hedonic prices and implicit markets: product differentiation in pure competition', Journal of Political Economy, Vol. 82, No. 1, pp.34-55.

Rysman, M. (2009) 'The economics of two-sided markets', Journal of Economic Perspectives, Vol. 20, No. 3, pp.125-143.

Scott, C.A. and Yalch, R.F. (1980) 'Consumer response to initial product trial: a Bayesian analysis', Journal of Consumer Research, Vol. 7, No. 1, pp.32-41.

Serricchio, V. (2013) In 2012 Smartphone Users Spent US\$ 8 billion for Paid Apps in the Top 5 App Platforms, 22 January [online] http://www.research2guidance.com/in-2012-smartphoneusers-spent-us-8-billion-for-paid-apps-in-the-top-5-app-platforms/ (accessed 11 February 2015).

Shapiro, C. (1983) 'Premiums for high quality products as returns to reputations', The Quarterly Journal of Economics, Vol. 98, No. 4, pp.659-680.

Shapiro, C. and Varian, H. (1999) Information Rules: A Strategic Guide to the Network Economy, Harvard Business School Press, Cambridge.

Smith, M.D. and Telang, R. (2009) 'Competing with free: the impact of movie broadcasts on DVD sales and internet piracy', MIS Quarterly, Vol. 33, No. 2, pp.321-338.

Spriensma, G.J. (2012) 2012 Year in Review, Distimo Report [online] http://www.distimo.com (accessed 11 February 2015).

Standifird, S.S. (2001) 'Reputation and e-commerce: eBay auctions and the asymmetrical impact of positive and negative ratings', Journal of Management, Vol. 27, No. 3, pp.279-295.

Tellis, G.J. (1986) 'Beyond the many faces of price: an integration of pricing strategies', Journal of Marketing, Vol. 50, No. 4, pp.146-160.

Thompson, G.L. and Teng, J-T. (1984) 'Optimal pricing and advertising policies for new product oligopoly', Marketing Science, Vol. 3, No. 2, pp.148-168.

VisionMobile (2012) Developer Economics 2012, June [online] http://www.visionmobile.com/ product/developer-economics-2012/ (accessed 11 February 2015).

Wei, X. and Nault, B.R. (2013) 'Experience information goods: version-to-upgrade', Decision Support Systems, December, Vol. 56, pp.494-501.

Williams, J.R. (2009) Mobile Computing: Predictions on Sustainable Advantage, Research Showcase Paper 541, Tepper School of Business, Carnegie Mellon University. 
Wooldridge, J.M. (2002) Econometric Analysis of Cross Section and Panel Data, The MIT Press, Cambridge, MA.

Yoon, E., and Lilien, G.L. (1985) 'New industrial product performance: the effects of market characteristics and strategy', Journal of Product Innovation Management, Vol. 2, No. 3, pp.134-144.

\section{Notes}

1 Data sources: http://www.pocketgamer.biz/metrics/app-store/?mpage=appcount;

http://www.appbrain.com/stats/number-of-android-apps;

http://techcrunch.com/2014/06/02/itunes-app-store-now-has-1-2-million-apps-has-seen-75billion-downloads-to-date/; http://www.techrepublic.com/article/google-play-v-apple-appstore-the-battle-for-the-mobile-app-market/; http://www.statista.com/statistics/281106/number-of-android-app-downloads-from-googleplay/.

2 Note that which group should be subsidised also depends on segment's direct price elasticity and the size of the two groups (Rochet and Tirole, 2003; Parker and van Alstyne, 2005; Eisenmann et al., 2006).

3 The full list of developers in our sample belonging to the category of giant developers with established worldwide notoriety is provided in Table 1.

4 The number of apps is 299 . However, only 16 apps are available in the top ten rankings of two or three stores. Therefore, the number of statistical units is 315 .

5 Note that Blackberry World actually adopts a 0 -to-5 scale. However, this is not a relevant issue in our sample as no rating equal to zero is observed.

6 Note, in fact, that the rating of an app might be affected by the price of the same app as a higher price might create higher expectations of consumers, who will be more likely to complain about product flaws and provide lower ratings to the given app. Therefore, by excluding the rating of the given app from developer rating computation, we reduce the risk of incurring in reverse causality problem, while still having a measure of reputation at the developer level.

7 In our sample there were a few cases of developers marketing only one app. According to our procedure, they were considered as not having a rating. This should not create much distortion, as it is reasonable that most of developers marketing only one app are less able to consolidate a reputation in a store via online mechanisms than developers marketing more apps.

8 Note that the process of homogenising app classification into thematic categories is quite simple in our dataset because the three stores have implemented very similar category systems.

9 We also introduced the total number of apps available in each distribution platform at a given week. We can reasonably assume that competition will be higher (and, thus, price will be lower) in a store where a higher number of apps are available. This is further supported by the fact that the average number of apps per developer in our sample is 1.32 . However, we removed this variable due to very high positive (negative) correlation, i.e., $0.82(-0.86)$, with the dummy App Store (Blackberry World). In fact, a perfect ranking of the three stores (in sequence, App Store, Google Play and Blackberry World) was observed in all the weeks.

10 The dummies chosen as baseline variables are Blackberry World, No Rating Developer and Games for distribution platform, rating and category variable types, respectively. In addition, the first Friday is chosen as baseline with regard to the temporal dummies. 